\title{
O ensino de leitura na perspectiva do professor e pesquisador Chistophe Ronveaux
}

\section{Teaching reading according to the professor and researcher}

Christophe Ronveaux

https://doi.org/10.34112/2317-0972a2016v34n68p155-166

\section{INTRODUÇão}

Entrevista com Christophe Ronveaux, professor da "Faculté de Psychologie et des Sciences de 1'Éducation" (FPSE), na Universidade de Genebra (UNIGE). Ronveaux é um dos membros do grupo de pesquisa GRAFE (Groupe de recherche pour l'analyse du français enseigné). Esta entrevista foi realizada pela professora Cleide Inês Wittke, por ocasião de seus estudos de pós-doutorado, cujo objetivo consiste em criar uma interface entre as realidades genebrina e brasileira no que tange ao ensino de língua - em especial, no que se refere à formação inicial e continuada do professor de línguas. ${ }^{1}$

\section{ENTREVISTADo}

Professor e pesquisador da FPSE, na Universidade de Genebra, Christophe Ronveaux realiza suas pesquisas no campo da linguagem, investigando questões

1. O presente trabalho faz parte do projeto de pesquisa intitulado: "Interface entre as teorias didáticas das línguas e transposição didática na formação inicial e continuada do professor de línguas”, aprovado e financiado pelo governo federal, via Coordenação de Aperfeiçoamento de Pessoal de Nível Superior (CAPES), no ano de 2015, na Universidade de Genebra. 
pertinentes ao ensino e à aprendizagem de leitura e de literatura, via gêneros de texto e sequências didáticas, com ênfase na literatura juvenil. Há vários anos, Ronveaux vem realizando estudos interessantes na área da formação de professores de francês, tendo como foco o objeto de ensino, o objeto ensinado e a atuação do professor em sala de aula, sempre com ênfase em questões voltadas ao léxico, ao vocabulário, a estratégias de leitura e ao ensino de literatura nos anos iniciais. Dentre suas inúmeras publicações, destacamos duas, ambas produzidas e publicadas pelos membros do grupo de pesquisa GRAFE: Groupe de recherche pour 1'analyse du français enseigné. Des objets enseignés en classe de français. Le travail de l'enseignant sur la rédaction de textes argumentatifs et sur la subordonnée relative (2009), organizada por Bernard Schneuwly e Joaquim Dolz ${ }^{2}$, com colaboração de diversos pesquisadores da UNIGE, inclusive com a participação de Ronveaux. A outra intitula-se: La lecture enseignée au fil de l'école obligatoire. L'exemple genevois (2014), organizada por Thérèse Thévenaz-Christien, com colaboração de Ronveaux.

\section{ENTREVISTADORA}

Cleide Inês Wittke é doutora em Linguística Aplicada pela PUC-RS, com estágio de doutoramento-sanduíche em Transposição Didática na Universidade Paul Verlaine, em Metz-França. É professora Adjunta na Universidade Federal de Pelotas (UFPEL) e atua no Centro de Letras e Comunicação. No ano de 2015, realizou pesquisa de pós-doutoramento sobre a Formação Inicial e Continuada do Professor de Línguas, com base na Didática das Línguas e na Transposição Didática, na Universidade de Genebra. Coordena o projeto de pesquisa intitulado: "O texto/gênero textual como objeto de estudo no ensino de língua: estratégias para desenvolver a capacidade leitora e seus efeitos na expressão escrita”. Seus trabalhos estão centrados em temas como ensino de línguas; formação inicial e continuada de professores; estratégias de leitura, de produção escrita e oral e de ensino de gramática; modelização de gêneros textuais e sequências didáticas; análise e produção de material didático. Além de vários artigos publicados em periódicos e colóquios, Cleide Inês Wittke também publicou três livros: Ensino de língua materna: PCNs, gramática e discurso (2007), O efeito discursivo da descrição escolar em manuais de

2. Os dois são professores ordinários da FPSE e foram o supervisor e o cossupervisor da entrevistadora no seu projeto de pesquisa de pós-doutorado na UNIGE. 
língua estrangeira (2011) e Ensino de língua e formação docente. Reflexão teórica e diálogo com professores (2015).

CIW - Sob uma perspectiva da engenharia didática ${ }^{3}$, como os futuros professores de francês são formados, tendo a leitura como objeto a ensinar e como objeto ensinado? Nesse contexto, no seu ponto de vista, quais são os saberes e o saber-fazer fundamentais para ensinar a ler de maneira competente?

Ch. R. - Então, é uma questão bastante complexa. Inicialmente, vou responder do ponto de vista da minha função de formador de professor no quadro de um Curso que dou na Faculdade de Psicologia e de Ciências da Educação sobre o "Ensino continuado da leitura”. Eu organizo esse Curso em duas grandes partes. Uma primeira etapa que trabalha essencialmente sobre a tarefa, ou seja, sobre como formular uma questão, uma ordem, um comando. Ensino sob a perspectiva de como utilizar a língua de modo a organizar um quadro de trabalho em torno da compreensão em leitura. Não sob o enfoque do modo como se faz as crianças compreenderem um texto, mas como organizar um espaço de trabalho onde vamos ensinar a compreensão em leitura. Não se trata da mesma coisa.

Essa é a primeira parte. Então, é um trabalho sobre a tarefa, sobre a língua com a qual eu organizo essa tarefa, e a língua com a qual eu ajudo, eu ensino, eu realizo meu trabalho no Curso. Eu faço esse percurso em minhas aulas. Este é um primeiro grande trabalho: qual tarefa, como formular um exercício e por que fazê-lo? E é exatamente esse por que fazer que, no meu ponto de vista, é o mais interessante.

Passamos, então, à segunda parte desse Curso. Na segunda etapa, eu falo do livro para os jovens, da literatura juvenil. A partir de milhares de publicações existentes no gênero, eu dou alguns identificadores, algumas pistas aos futuros professores para dizer "este é um bom livro", "este livro é bom livro"... Mas o importante é saber: "Por que são bons livros? O que eles trazem? Sobre o que e como abordam?".

3. O termo "engenharia didática" retoma sua origem na engenharia, cuja função é pesquisar e desenvolver mecanismos, produtos e ferramentas técnicas complexas, planificando formas sociais de trabalho. A engenharia diz respeito a processos e métodos de criação de soluções para problemas de diferentes setores sociais. Já a didática é uma disciplina de ação voltada a buscar soluções para problemas encontrados nos processos de ensino e de aprendizagem.

A engenharia didática busca criar ferramentas para facilitar a aprendizagem, bem como orientar os gestos dos professores. Nesse contexto, as engenharias da leitura, do oral e da escrita concentram-se em formular, ajustar e efetuar estratégias voltadas tanto ao ensino da competência leitora, quanto da produção oral e escrita.

A engenharia didática tem o objetivo de definir e lidar tecnicamente com tarefas dos alunos para aprender, de coordenar ações dos professores no processo de ensino e de elaborar dispositivos didáticos, estratégias que possam solucionar problemas encontrados no ensino de língua (DOLZ, no prelo). 
O ensino de leitura na perspectiva do professor e pesquisador Chistophe Ronveaux

Antes de responder a essa questão, eu faço os formandos reaprenderem a amar a leitura. É uma espécie de degustação pela leitura, pelo livro. Posso dizer que é um interesse por um suporte que pode interessar, pode agradar, chamar a atenção, trazer prazer pela leitura, buscando superar as questões que acabam afastando o aluno da prática de ler.

$\mathrm{Na}$ segunda parte do Curso, eu apresento muitas obras, muitas coleções para jovens, e eu entro pelo suporte de compêndios (compositos). Trabalho com o livro voltado para a juventude. Eu entro com esse suporte complexo que são obras muito boas, mas que também são pequenas joias com grandes desafios. Esses textos são bons, e as imagens são articuladas com o texto. Eu faço com que os formandos leiam em conjunto muitos livros da literatura juvenil, material que lhes dá subsídio para que se organizem a partir da enorme quantidade que atualmente eles têm à disposição para ler e trabalhar em aula.

E essa entrada no livro juvenil é feita pela leitura. Eu leio, mas eu leio na perspectiva do tchan... daquilo que é interessante, que é fácil, que é difícil. E levo os formandos a se questionarem: Por que é aparentemente fácil, mas os alunos podem encontrar dificuldades em entender esta obra?

De qualquer forma, cabe destacar que não fazemos uma análise a priori, não é esse o caso. Trata-se, acima de tudo, de uma identificação, de ligação difícil, problemática, interessante, seja do ponto de vista da imagem, seja a partir da relação estabelecida, perguntando: o que é isto (texto escrito), e o que é isto (imagem)? É um sol e uma lua, uma menina de saia plissêe - enfim, há um código simbólico de cores, há o movimento com que ela se embala no balanço; em sintese, trabalho apontando e questionando todas essas convenções que parecem simples, todavia são muito importantes, pois mudam de acordo com a cultura, alterando seus sentidos.

E eu me interrogo sob qual convenção eu posso construir a alucinação sobre/do mundo. É em torno dessa ideia que abordo o ensino da leitura. Certamente, eu procuro trabalhar o gênero, o da narração, por exemplo, com os formandos, mas também abordo outros tipos de textos. Não se trata de uma análise a priori, como faz meu colega de matemática, em que há uma ordem clara/objetiva e essa implica tal ou tal procedimento, e as crianças escolhem e realizam o procedimento adequado. Já para nós, a análise a priori torna-se complicada, uma vez que a convenção de alucinação não é fixa e varia em cada cultura.

Certamente, temos valores simbólicos em função da região, do país, em função da cultura, da língua, e esses aspectos complicam tais atividades e, de modo particular, os estudos da literatura juvenil. Não se pode fazer uma análise prévia, pois elas são orientadas, sobretudo, em torno às vezes do conteúdo ou, outras vezes, da forma, começando pelo lugar da obscuridade, ou seja, onde há dúvidas. A base é: "Eu não compreendo isso, então, procuro 
compreender quais são os elementos que eu posso ativar para entender a cor, a composição, a construção de uma frase, o léxico. Sintetizando, acredito que, com minha explicação sobre a construção da tarefa e da escolha do suporte, tenha respondido parte da sua questão. De um lado, como organizar o trabalho e, de outro, a partir de qual suporte organizá-lo.

Quando digo isso parece que não explico nada, pois não falei do objeto ensinado, do saber e do saber-fazer fundamentais, uma vez que fiz aflorar outros aspectos importantes ao ensino da leitura. No que diz respeito ao saber e ao saber-fazer, digo que há saberes ligados ao texto è à sua natureza, há saberes gerais, enfim, o gênero do texto pode ajudar a organizar o conteúdo, por exemplo, ou a construir um horizonte de expectativas e a formular hipóteses.

Justamente, falamos sobre o que é uma história. O que é um narrador que conta uma história? Trabalhamos todas essas pequenas coisas que fazem com que uma narrativa possa se tornar complicada porque o narrador, por exemplo, cerca, enriquece, envolve e se encaixa em um outro. Um pouco como o conto "Mil e uma noites". Hoje, na literatura juvenil, há muitas narrativas encaixadas (sobrepostas) ou com flashback, em que uma história, ao ser contada, se mistura com outra; ou ainda há personagens com ideias bizarras, ou mesmo narrativas com estereótipos, como é o caso do "Le jeu sur le roi".

Hoje em dia, a literatura juvenil não é simples, e os suportes dos compêndios (compositos), em particular a imagem e o texto, provocam novas dificuldades com a diferente maneira de fazer os alunos se interessarem, se engajarem nessa leitura, que não é uma atividade simples.

Do ponto de partida é isso. É necessário observar de modo mais preciso a natureza da obra, a estrutura de um suporte e então o saber textual ligado a ele. O saber textual apresenta-se em diferentes níveis: no macro, no nível do gênero, e também no nível microscópico, no tipo da cor, da pontuação, do léxico, da sintaxe. E é a combinação de todos esses níveis de complexidade que cria a necessidade, no meu ponto de vista, de encontrar uma tarefa que ... tak!! ... que faz com que a criança entre na obra. E esse é o dispositivo de saber que defendo, pois acredito que o saber e a tarefa são evidentemente interligados entre si.

Nessas condições, se a gente identifica o saber, é então possível construir um dispositivo que possa ativá-lo, o qual vai permitir que a criança ative esse saber. Ou simplesmente construir um pequeno método que ensine. Um exemplo é o conhecido método de leitura pela fragmentação. Entrar em um texto pela fragmentação quer dizer que vou começar a trabalhar com esse texto, mas vou suprimir o título, por exemplo.

Ou posso entrar por meio de uma página como esta (o professor mostra um livro), por exemplo, e levo os alunos a se interrogarem sobre o início, o meio e o fim. E também 
a se questionarem sobre qual é o personagem (nesse caso, um menininho) e ao mesmo tempo sobre algo bizarro, há um jovem que fala, uma garota... vou levar as crianças a entrarem na obra não através da capa, do título, mas a partir de uma página qualquer do livro. E eles são obrigados a refletir, a questionar sobre tudo o que há nessa página: imagem, texto, cor, ou somente por meio da imagem, com o objetivo de criar o texto ou de desenhar a imagem (no caso dos alunos menores). Cabe destacar que não se trata de fazer igual como está no livro, pois não estimulo a cópia, mas o objetivo é criar instrumentos de leitura que questionem o texto. Para mim, o foco é sempre o texto, e defendo a entrada textual. Quando se entra no texto pelo fragmento, rapidamente, ele me dá ideias para construir o todo dessa narrativa. Geralmente, uma narrativa é contada por um narrador.

Há uma relação bem estreita entre, de uma parte, o saber textual e, de outra, o dispositivo para a fragmentação. Por exemplo, para levar a criança a entrar, quer dizer, a criar condições de uma alucinação voluntária, falo de alucinação com base no termo de Vigostky, eu alucino, eu imagino, eu crio um mundo que não é o meu a partir de uma palavra, de um texto, com base em uma imagem articulada a um texto. Não é a imagem que me dá o retrato do mundo. É uma imagem e um texto os quais me ajudam a construir um outro mundo, que não é o meu.

Não é uma atividade banal, simples, mas uma atividade complexa de leitura. É uma alucinação voluntária de um indivíduo, e, como é voluntária, é construída a partir da convenção textual. O saber-fazer (savoir-faire) fundamental pode ser formular uma hipótese quando há uma intriga, ou ainda apoiar-se no contexto para identificar uma palavra do vocabulário. Por exemplo, posso suspender provisoriamente um instrumento que formulei na minha cabeça e submetê-lo a um grande grupo, a um coletivo.

Essas são estratégias de leitura que eu procuro ensinar e que fazem parte do saber-fazer do leitor. É o saber do texto, mas também o saber-fazer estratégico do leitor que questiona o texto, que faz uma interpretação e que diz: "Espera! Pode ser que não seja bem dessa forma, mas eu penso assim". Eu penso assim, mas dizer isso a crianças de 6, 7, 8 anos não é uma tarefa simples. É aceitar que seu instrumento forjado na cabeça é compartilhado com os outros, e ele é provisório, até que se prove o contrário, ou até que surja um indício seguinte.

Essa é uma atividade que demanda muitos níveis diferentes de conhecimento, uma teoria da prática, mas também uma prática da teoria. Quando eu construo meu dispositivo de ensino de leitura, eu sei que tal palavra do vocabulário é complicada para entender o todo, sei que os anafóricos me ajudam a construir um personagem, mas a relação desse personagem com os outros presentes na história também é importante. Tudo isso são 
saberes sobre o texto, mas também um saber-fazer por parte do professor que pensa em um dispositivo para construir seu ensino de leitura. O Curso é construído nesse modelo, colocando em cena a capacidade argumentativa e os efeitos do dispositivo sobre um leitor. É preciso convencer meus alunos (futuros professores) disso.

CIW - Há vários anos, o GRAFE efetua pesquisas investigando sobre os processos da leitura e da escrita. Você poderia relatar os principais resultados obtidos com os estudos sobre a leitura e suas implicações na aula de francês?

Ch. R. - Como você sabe, conforme as reuniões da equipe de pesquisas, o trabalho sobreo processo de escrita é muito bom, mas não faço parte desse grupo de estudo. Toda entrada pelo gênero de texto como um instrumento que ajuda a construir a escrita é realmente muito produtivo. Você pode organizar uma progressão, organizar os objetos a ensinar. Ao contrário da ideia expressa por Boileaus: "Aquilo que é bem concebido, enuncia-se claramente e as palavras fluem facilmente", o qual defende o ponto de vista de que se deve pensar primeiro e depois escrever. Para mim, é justamente o inverso. Ajuda primeiro a escrever para depois pensar bem! Exatamente o sentido oposto!

E, no que diz respeito à leitura, defendo que, ao invés de primeiro pensar, deve-se primeiro aprender a ler, ou seja, a construir o pensamento a partir dessa convenção textual, da linguagem, da cultura, e, com base nessa convenção, começar então a construir o estado de alucinação voluntário de que fala Vygotski. Na organização do meu Curso, não se trata do processo de leitura - eu não conheço nada sobre o processo de leitura, pois não sou psicólogo. Assim, as pesquisas do GRAFE não abordam sobre o que se passa na cabeça da criança; ao contrário, os estudos do GRAFE mostram que a criança, em uma forma escolar, produz conhecimentos. E o GRAFE mostra em suas pesquisas, em particular as do GAFELect, que é fundamental construir, a partir dessa investigação, uma descrição, de maneira mais fina possível, daquilo que se produz na escola, ao longo da escolaridade obrigatória.

Existe a ideia de que se prevê uma continuidade no ciclo um, no ciclo dois, no ciclo três e depois no pós-obrigatório; então, quais medidas didáticas devemos tomar para criar e manter essa sequência? O que se faz em leitura, como se avança, não é um processo de desenvolvimento, mas é um processo sócio-histórico de construção da competência de

4. Como já dito na introdução, trata-se do "Groupe de recherche pour l'analyse du français enseigné", composto por vários grupos de pesquisa, incluindo o GRAFELitt (de literatura) e o GRAFELect (de leitura), ambos citados pelo professor Ronveaux na sua entrevista.

5. "Ce qui se conçoit bien s'enonce clairement et les mots on célebre." 
O ensino de leitura na perspectiva do professor e pesquisador Chistophe Ronveaux

leitor. Sobre isso eu falo no Curso. E acredito que a escola, hoje, no que tange ao ensino da leitura, ainda se baseia no modelo tradicional, que é direcionado à literatura como objeto de seleção. Sob esse enfoque, seleciona isso (concreto = palavra-coisa) e isso (abstrato = palavra-coisa), reservando o ensino da literatura à elite.

Essa seleção tem como base a perspectiva do concreto, da transparência da linguagem, sobre a qual falamos bastante no Curso. Essa transparência consiste na definição de que uma palavra é igual a uma coisa; depois fazemos a mesma abordagem com o abstrato, no fim do primário. Com o ensino do abstrato continua-se a dizer que uma palavra, por exemplo, o nazismo, é igual a uma coisa (o professor desenha o símbolo), seguindo o mesmo procedimento no ensino do concreto, pois as palavras são vistas como transparentes. Essa concepção torna-se mais complicada quando não se está no enfoque nem do concreto, nem do abstrato, nem da literatura, sobretudo no que tange à leitura literária. Essa última ocorre quando é dado um instrumento para aprender a ler não simplesmente uma palavra ou uma coisa, mas a partir da concepção de que a palavra é igual ao mundo.

No entanto, as investigações realizadas pelo GRAFELect, e também pelo GRAFELitt, mostram que o mundo é uma evolução, um processo de progressão, que é construído pela escola, através da abertura pela literatura. Então, preparamos oformando para sair dessa abordagem, orientando-o a evitar essa ruptura, na busca de assegurar uma progressão. Isso eu posso fazer em minhas aulas, durante a formação. Os futuros professores são motivados a não fazer uma simples leitura banal do texto, mas a construir uma leitura literária, aquela dita inferencial, a qual já pode ser iniciada com os pequenos, nas séries iniciais. Essa é a progressão espiral.

O meu Curso segue justamente no interesse da literatura juvenil, pois, por meio dessa literatura, posso trabalhar a leitura, sob a perspectiva da progressão espiral, em todos os níveis, até chegar ao ensino obrigatório. Essa é a primeira dimensão. Na segunda perspectiva, a da literatura propriamente dita, o ensino de leitura é mais complicado por ser um objeto de seleção, o que, no meu entender, é bastante complexo, pois, quando você está dentro do sistema de ensino, não pode fazer outra coisa. Portanto, talvez seja preciso ter um objeto que não seja a literatura. Talvez se possa ver sob a perspectiva da leitura científica, mas não resolve sendo uma abordagem científica. Talvez se possa trabalhar sob a perspectiva da fronteira entre aquilo que é literatura e aquilo que não é literatura.

Por exemplo, na Europa, para nós, é muito importante o testemunho. O testemunho no ato de relatar, e certamente também há, e estou de acordo, as histórias, pois não se trata da mesma coisa. Quando se narra, tudo vai bem e segue-se na busca de uma construção curricular que articula, que contrasta os textos que contam e aqueles que relatam. 
Isso, para instruir as crianças a compreender que, em nome do falso e do verdadeiro falso, somos obrigados a falar da referência. Em todo caso, é necessário propor outras formas textuais que não sejam da literatura.

E, no Curso, eu sou a favor de uma seleção, pois defendo que toda pessoa que presencia um fato pode testemunhá-lo. Toda pessoa que vivencia um trauma de imigração ou uma catástrofe natural, por exemplo, pode testemunhar, pode falar, pode expor oralmente e, por que não, por escrito, essa emoção, essa dor, essa dificuldade de ser e de guardar seu lugar no mundo, uma vez que tenha vivido essas experiências terríveis. Isso acaba sendo bem aceito quando não estamos falando de literatura, mas se trata de uma atividade de linguagem que contrasta uma ação particular, que fica bem distinta entre o ato de relatar o o de narrar.

Há, no entanto, outras possibilidades a serem efetuadas, por exemplo, pois podemos trabalhar com o texto informativo, por que não? Mas o interesse não é o conteúdo; sim, ele está ali, mas vou focar minha atenção na pequena frase: como se faz para ler e para se interessar pela palavra, e depois disso a ação alucinação voluntária será facilitada. Na sequência, se pensa na estrutura textual, na construção do léxico e da sintaxe etc. Certamente, as fontes da linguagem vêm em primeiro plano, e é sob esse sentido que ensino os futuros professores a trabalharem sob o ponto de vista do texto e de estratégias de leitura.

CIW - Você poderia explicar qual é diferença entre o saber a ensinar e o saber para ensinar no processo de formação do professor de línguas?

Ch. R. - Já respondi essa questão, mas vou especificar que o saber a ensinar está mais centrado nos elementos de linguagem, textuais, icônicos, enfim, são saberes geralmente do nível macroestrutural do texto, mas também do nível da microestrutura, como é o caso dos anafóricos. Também há interesse pela noção de personagem, pelo fato e por sua veracidade. Podemos trabalhar com of uturo professor os faits divers ${ }^{6}$. No Curso, propus que lessem em torno de trinta faits divers, classificando-os (como você viu durante nossas aulas). É uma proposta de ensino bastante interessante, e há muitas coisas a observar: o fato, os valores veiculados por esse fato, a extensão do texto, a complexidade do vocabulário usado. Os saberes a ensinar são saberes bastante complexos e muito heterogêneos. Penso que eles devem ser investigados cada um nos seus diferentes níveis e, para tanto, é preciso ajudar o professor a tomar decisões.

6. O faits divers é um gênero de texto que aborda assuntos gerais e apresenta características semelhantes ao nosso artigo de opinião, no campo midiático brasileiro. 
O saber do professor, e do conhecimento de saber mais sobre o ensino, consiste em organizar no tempo uma sequência de ensino, como uma unidade de trabalho. Esses são saberes do professor (voltados ao saber para ensinar), são de extrema importância. É um saber que remete ao tempo, à estruturação do tempo com base na hierarquia dos objetos que ele tem à disposição para construir uma progressão. A noção de tarefa consiste nas atividades que o professor constrói com base no tempo e está diretamente implicada com os objetos a ensinar que são hierarquicamente construídos. Para mim, esse elemento (a elaboração da tarefa) é o mais importante de todos.

CIW - No seu ponto de vista, qual é a relação entre ensinar a ler e a escrever? Pode-se dizer que um gesto didático depende do outro e que são separados somente por uma questão didática?

Ch. R. - Não vejo assim. Isso é complicado. Há uma pressuposição em nossa sociedade da escrita (letrada), ou seja, há uma convicção de que devemos ajudar a criança a passar do oral ao escrito. Para mim, é exatamente o inverso. Acabamos não questionando essa concepção porque nos parece normal que a oralidade esteja a serviço da escrita, ou ainda que o oral esteja subordinado à escrita, já que essa última é vista como o primeiro estado da cultura.

Os pequenos não sabem escrever, e o objetivo é, dessa forma, ensiná-los a escrever. Mas, quando se tem um texto, não é bem assim. O texto é tanto oral quanto escrito. Então, como podemos interrogar essas duas modalidades, uma vez que pode ser tanto icônico como textual? Essa é uma complexidade interessante do nível semiótico, pois há convenções que não são as mesmas em diferentes culturas, ainda que se possa estar em acordo no nível da linguagem.

Na perspectiva da esfera da atividade, a partir do quadro da teoria, que é bem eficaz e busca explicar ess a complexidade, ao questionar em qual esfera de atividade eu estou, $o$ Curso responde a questões simples tais como: $O$ faits divers serve para quê? É produzido por quem? Dirigido a quem? A que questão eu respondo quando escrevo um faits divers? Dentre outros aspectos dessa natureza.

CIW - Como pode o professor avaliar a progressão da leitura do aluno? Essa avaliação é possível?

Ch. R. - Sob a abordagem da progressão espiral, ele pode. Não é simples, mas o professor pode, por exemplo, realizar exercícios que avaliam a capacidade de fazer inferência ou efetuar exercícios bem eficazes, como é o caso do resumo. Se souber fazer uma boa 
construção e condução com o aluno, no oral e no escrito, a partir de uma relação com o coletivo ou individualmente, o professor terá bons resultados no ensino da leitura.

Com base nesse trabalho, o professor pode transmitir um resumo para que o aluno compreenda uma história. Eu compreendo e você me passa o seu resumo para ver se eu compreendi a mesma coisa que você. Trata-se de uma situação de comunicação a partir da qual o resumo não é visto somente como uma resposta a uma solicitação do(a) professor (a), mas está engajado em uma situação de comunicação voltada à informação que o aluno leu, ou não. Temos um dispositivo que coloca em ação no mínimo dois indivíduos e com um coletivo da turma que faz um trabalho articulando o oral com a escrita. Pelo oral, eu digo ao outro o que entendi, via escrita.

CIW - Para finalizar, que conselho você dá ao professor brasileiro para estimular o aluno a ler?

Ch. R. - Sugiro que o professor coloque em cena a atividade de leitura, já que tem o compromisso de criar possibilidades, de criar um enigma que permite colocar os alunos em situação de jogo, na leitura. Trata-se de criar um enigma em torno da leitura, pois essa deve ser interessante, divertida, por constituir-se em uma situação de questionamento, de investigação.

É preciso criar disposição, condições para o suspense enquanto escondo alguns dados, mostrando outros, com o objetivo de criar a necessidade de ser intrigado. Ser intrigado significa: "Eu adoro ser envolvido em e com uma intriga". Isso, no sentido de que o aluno aceita um momento de suspense, deixando flutuar sua atenção para tentar eleger todas as hipóteses que lhe permitem construir, sobretudo progressivamente, a respeito de uma intriga, de um jogo, de um mundo alucinado. O professor deve motivar a leitura nos jovens estudantes brasileiros, colocando em ação esse suporte como uma fonte de questionamento, de reflexão, e também como fonte de emoção e de suspense.

É importante construir um dispositivo de ensino que possa despertar o prazer no fato de o leitor ser intrigado diante de uma situação em que não se têm as respostas prontas, mas essas vão sendo construídas ao longo do jogo, na medida em que se desvenda a intriga. No meu Curso, ressalto sobre a importância de motivar no aluno o prazer de socializar sua hipótese com o outro. Nesse sentido, apostamos na eficácia e no prazer da leitura a partir do engajamento do leitor no texto em estudo. 


\section{REFERÊNCIAS}

DOLZ, J. As atividades e os exercícios da língua: uma reflexão sobre a engenharia didática. No prelo. SCHNEUWLY, B.; DOLZ, J. Des objets enseignés en classe de français. Le travail de l'enseignant sur la rédaction de textes argumentatifs et sur la subordonnée relative. Rennes: Presses Universitaires de Rennes, 2009.

THÉVENAZ-CHRISTEN, T. (Org.) La lecture enseignée au fil de l'école obrigatoire. L'exemple genevois. Namur: Presses Universitaires de Namur, 2014.

VYGOSTKI, L. S. Pensamento e linguagem. São Paulo: Martins Fontes, 2008.

WITTKE, C. I. O efeito discursivo da descrição escolar em manuais de língua estrangeira. Pelotas: Editora e Gráfica Universitária da Universidade Federal de Pelotas, 2011.

. Ensino de língua materna: PCNs, gramática e discurso. Santa Cruz do Sul: EDUNISC, 2007. . Ensino de língua e formação docente. Reflexão teórica e diálogo com professores.

Saarbrücken, Deutschland: Novas Edições Acadêmicas (Verlang Editora), 2015.

Recebido em 02 de fevereiro de 2016 e aprovado em 15 de dezembro de 2016. 